\title{
EL SEGURO OBLIGATORIO DE LA LEY DE ORDENACIÓN DE LA EDIFICACIÓN
}

\author{
Yanet Puga Pérez \\ Juez Sustituta
}

Doctoranda en el Programa de Doctorado en Ordenación Jurídica del Mercado. UV.

Email: yanetpuga@hotmail.com

\begin{abstract}
RESUMEN: Entre la prolija normativa vigente destinada a la protección del derecho a la vivienda, recogido en el artículo 47 de la Constitución Española como un principio rector de la política social y económica, se encuentra el régimen especial del seguro decenal contenido en el artículo 19 y la Disposición adicional segunda de la Ley 38/1999, de 5 de noviembre, de Ordenación de la Edificación, orientado a garantizar a los adquirentes de un inmueble el resarcimiento de los daños ocasionados en el mismo por vicios de la construcción. En este trabajo se analiza, con perspectiva crítica, el régimen jurídico de tal garantía y su adecuación a la finalidad pretendida, tratando sucesivamente el alcance de la obligatoriedad de la suscripción del seguro, los daños excluidos de cobertura, los modos de cumplimiento de la obligación legalmente impuesta y las sumas aseguradas, para terminar con el examen de las medidas coactivas destinadas a obtener el cumplimiento por el promotor de su obligación legal.
\end{abstract}

Palabras clave: vivienda, seguro, daños, vicios estructurales, promotor profesional, autopromotor, medidas coactivas.

ABSTRACT: Between the abundant active regulations destined to protect the right to housing, recognized in article 47 of Spanish Constitution as a vector principle of social and economic policy, it's decennial insurance special regime, included in article 19 and second additional provision of law $38 / 1999,5^{\text {th }}$ November, of Edification Ordination, oriented to guarantee to the purcharsers of a property a compensation for damages caused on this by construction vices. In this work it's analyzed, with a critical perspective, the legal regime of this guarantee and its adecuacy to the intended purpose, treating successively the scope of obligatory insurance subscription, the damages excluded from coverage, the ways to comply legally imposed obligation and the secured sums. It finishes with the exam of coercive measures destined to get that promoter comply his legal obligation.

Keywords: Housing, insurace, damages, construction vices, professional promoter, self-promoter, coercive measures. 
SUMARIO: I. ANTECEDENTES, CLASES Y PLAZOS DE DURACIÓN DEL SEGURO PREVISTO EN LA LOE. II. ÁMBITO DE ObLIGATORIEDAD: A) Delimitación positiva. B) Exclusiones: por razones objetivas y subjetivas. III. EXCLUSIÓN DE cobertura. IV. Modos De Cumplimiento. V. Sumas aseguradas y Vía De Regreso. VI. Medidas Coercitivas

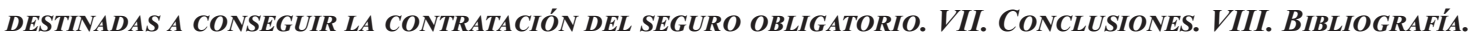

\section{ANTECEDENTES, CLASES Y PLAZOS DE DURACIÓN DEL SEGURO PREVISTO EN LA LOE}

Es un principio del derecho de obligaciones, dotado de concreción positiva y no exceptuado de aplicación en el ámbito de la responsabilidad civil por vicios de la construcción, el de que todo deudor debe responder de las obligaciones que le incumben, independientemente de su origen (legal, contractual o extracontractual), con todos sus bienes presentes y futuros (artículo 1.911 del Código Civil -en adelante, CC-). Este principio, doctrinalmente denominado «de responsabilidad patrimonial universal», resulta aplicable, como no podía ser de otra manera, a los diversos agentes de la edificación con respecto a su obligación legal de responder de los daños materiales ocasionados por defectos de construcción. No obstante, para prevenir la eventualidad de que tales agentes estén incursos en situación de insolvencia, real o fingida, la Ley 38/1999, de 5 de noviembre, de Ordenación de la Edificación (en adelante, LOE) establece en su artículo 19 la prestación obligatoria de ciertas garantías. Tales garantías se concretan en un seguro, que puede ser de daños, de caución o, tras la modificación llevada a cabo por la Ley 20/2015, de 14 de julio, de Ordenación, Supervisión y Solvencia de las Entidades Aseguradoras y Reaseguradoras, también de garantía financiera ${ }^{1}$.

No es esta la primera vez que el legislador estatal impone la constitución de garantías para responder de los defectos de la construcción. El antecedente inmediato lo encontramos en el artículo 111.3 del Decreto 2114/1968, de 24 de julio, por el que se aprueba el Reglamento de Viviendas de Protección Oficial, que, en desarrollo del artículo 27.4 del Real Decreto 2960/1976, de 12 de noviembre, por el que se aprueba el Texto Refundido de la Legislación de Viviendas de Protección Oficial², impuso al promotor la obligación de constituir un seguro para garantizar el cumplimiento de su obligación de ejecutar las obras de reparación que fuesen necesarias como consecuencia de vicios o defectos de construcción que se manifestasen en el plazo de cinco años desde la calificación definiti-

1 El establecimiento de un sistema de seguros obligatorios para garantizar el resarcimiento de los daños materiales causados en el edificio es destacado por la doctrina científica como una de las novedades más importantes introducidas por la LOE con respecto al régimen anterior en materia de responsabilidad civil por vicios de la construcción (el del artículo 1591 del CC). Así, CABANILLAS SÁNCHEZ, A. «La responsabilidad civil por vicios en la construcción en la Ley de Ordenación de la Edificación», Anuario de Derecho Civil, Madrid, 2000, p. 405.

2 El artículo 27.4 del Real Decreto 2960/1976 dispone que: «Si en el transcurso de cinco años desde la calificación definitiva de las viviendas del grupo I (tienen tal consideración aquellas para cuya financiación no se concedan subvenciones, primas, auxilios o anticipos por parte de las Administraciones Públicas con competencia en la materia) o de la terminación de las sociales (aquellas que sean calificadas como tales por las Administraciones Públicas correspondientes y reciban los beneficios legalmente establecidos por reunir las características técnicas y económicas y los condicionamientos subjetivos que se fijen reglamentariamente) se manifestaren vicios $o$ defectos de construcción que hicieren necesarias obras de reparación, podrá imponerse su ejecución al promotor o realizarlas a costa de éste. Para asegurar el cumplimiento, en su caso, de tal obligación, el promotor habrá de constituir una garantía en la forma y condiciones que se determine reglamentariamente». 
va de la vivienda como de protección oficial ${ }^{3}$, sin perjuicio del ejercicio de las acciones reguladas en los artículos 1591, 1909 y 1484 del CC.

El seguro que la LOE exige constituir es, a elección del tomador, un seguro de daños $^{4}$, de caución ${ }^{5}$ o de garantía financiera ${ }^{6}$, no un seguro de responsabilidad civil, sin perjuicio lógicamente de que pueda concurrir con el seguro de responsabilidad civil profesional que los agentes de la edificación suelen contratar ${ }^{7}$. Ello conlleva, en el seguro contra daños, que el siniestro se entienda producido por la simple producción del menoscabo derivado del vicio de la construcción, independientemente de a quien sea éste imputable, por lo que el asegurador no puede exonerarse de su obligación indemnizatoria alegando que el daño no es atribuible al tomador del seguro sino a otro agente de la edificación. El seguro exigido implica también que el asegurado (el adquirente de la vivienda), a la hora de exigir los derechos dimanantes del contrato, no tenga que demandar, previa o simultáneamente, además de a la compañía aseguradora, al agente que considere artífice del vicio, a fin de que se declare su responsabilidad civil.

El apartado 1 del artículo 19 de la ley fija los plazos de vigencia obligatoria de los mencionados seguros, que vienen a coincidir con los establecidos en el artículo 17.1 como plazos de garantía de buena construcción; por lo que son de diez años, para los daños ocasionados por defectos estructurales, de tres años, para los daños producidos por vicios o defectos de habitabilidad, y de un año, para los daños por vicios de ejecución que afecten a elementos de acabado ${ }^{8}$, contados desde la fecha de recepción de la obra sin reservas o desde la subsanación de éstas. En este último caso, la ley permite

3 Según el artículo 111.2.3 y 4 del Decreto 2114/1968: «Si en el transcurso de cinco años, desde la calificación definitiva, se manifestasen vicios o defectos de la construcción que hiciesen necesarias obras de reparación, podrá imponerse su ejecución al promotor o realizarlas a costa de éste.

Para garantizar el cumplimiento de las anteriores obligaciones, el Instituto Nacional de la Vivienda exigirá de los promotores que no tengan carácter oficial la constitución de un seguro bastante durante el plazo que se fije, y que no será superior al de los cinco años a que se refiere el apartado anterior.

Quedarán a salvo, en todos los casos, las acciones que puedan ejercitar los propietarios y adquirentes de las viviendas al amparo de los artículos 1.484 y siguientes, 1.591 y 1.909 y demás de pertinente aplicación del Código Civil».

4 El seguro contra daños, como su propio nombre indica, es aquél que cubre el riesgo de que un bien propiedad del asegurado (en este caso un edificio) sufra un menoscabo o deterioro.

5 La definición auténtica de esta modalidad de seguro se encuentra en el artículo 68 de la Ley 50/1980, de 8 de octubre, del Contrato de Seguro (LCS), "Por el seguro de caución el asegurador se obliga, en caso de incumplimiento por el tomador del seguro de sus obligaciones legales o contractuales, a indemnizar al asegurado a título de resarcimiento o penalidad los daños patrimoniales sufridos, dentro de los límites establecidos en la Ley o en el contrato. Todo pago hecho por el asegurador deberá serle reembolsado por el tomador del seguro».

Aunque ha sido bastante controvertida su naturaleza jurídica, y, en concreto, si se trata de una fianza o de un verdadero seguro, la doctrina se inclina por otorgarle carácter aseguraticio, pues el asegurador no se compromete a cumplir las obligaciones que el tomador deje insatisfechas, sino a resarcir los daños y perjuicios ocasionados como consecuencia de tal incumplimiento. Véase, YZQUIERDO TOSLADA, M: «¿Qué cubren en realidad los seguros de caución para la construcción en las cooperativas de viviendas? Un comentario disidente a la Sentencia del Tribunal Supremo (Pleno Sala Primera) de 13 de septiembre de 2013», Revista de la Asociación Española de Abogados Especializados en Responsabilidad Civil y Seguro, No 49, 2014, p. 31.

6 La garantía financiera es un pacto o contrato a través del cual se pretende dotar de una mayor seguridad el cumplimiento de una obligación, como puede ser un aval, una fianza o una hipoteca. No aparece regulado en la LCS, por lo que parece más correcta la denominación de «garantía financiera» que la de «seguro de garantía financiera.

7 Por el seguro de responsabilidad civil profesional o de explotación los agentes de la edificación aseguran la obligación de indemnizar a un tercero los daños y perjuicios ocasionados en el edificio en el que intervienen o en elementos ajenos al mismo (artículo 73 LCS).

8 El artículo 19.1 de la LOE, literalmente, establece que: «El régimen de garantías exigibles para las obras de edificación comprendidas en el artículo 2 de esta Ley se hará efectivo de acuerdo con la obligatoriedad que se establezca en aplicación de la disposición adicional segunda, teniendo como referente las siguientes garantías: 
sustituir el seguro por la retención del importe del 5\% del coste de la ejecución material de la obra, retención que puede practicar el promotor, que es quien viene obligado a satisfacer el precio al constructor. Se trata de una norma de escasa o nula eficacia cuando, durante el plazo de un año a contar desde la recepción de la obra, el promotor haya procedido a enajenar todos o parte de los elementos privativos en que aquella se haya dividido horizontalmente $y$, por tanto, sean otras personas las perjudicadas por los daños; pues, como dice CARRASCO PERERA, dicha retención no garantiza a éstas que tal cantidad vaya a ser destinada por el promotor a las obras de reparación que sea necesario realizar9. No se trata de que no exista la obligación legal de destinar el importe de la retención a las operaciones de subsanación de los defectos, sino de que, en caso de que el promotor no la aplique voluntariamente a ello, los adquirentes no tendrán más opción que el recurso a los tribunales para conseguirlo. En realidad, el precepto no supone ninguna garantía añadida para los adquirentes, quienes, ante la producción de daños en elementos de terminación o acabado y la negativa del promotor a dedicar la cuantía de la retención a su subsanación, lo único que pueden hacer es accionar contra el constructor, responsable legal de los mismos (artículo 17.1 LOE), y/o contra el promotor, responsable legal solidario (artículo 17.3 LOE).

\section{II. ÁMBITO DE OBLIGATORIEDAD}

\section{A) Delimitación positiva}

En la actualidad, conforme a lo dispuesto en la disposición adicional segunda de la LOE, únicamente es obligatorio el seguro decenal; es decir, aquel que protege al asegurado frente a los posibles vicios estructurales del edificio ${ }^{10}$. Por vicios de tal naturaleza se han de entender aquellos que afectan a elementos estructurales de la construcción ${ }^{11}$ y que comprometen directamente la resistencia mecánica o la estabilidad de ésta, bien sea de presente o previsiblemente en un futuro (siempre durante el plazo de garantía de diez

a. Seguro de daños materiales o seguro de caución, para garantizar, durante un año, el resarcimiento de los daños materiales por vicios o defectos de ejecución que afecten a elementos de terminación o acabado de las obras, que podrá ser sustituido por la retención por el promotor de un 5\% del importe de la ejecución material de la obra.

b. Seguro de daños materiales o seguro de caución, para garantizar, durante tres años, el resarcimiento de los daños causados por vicios o defectos de los elementos constructivos o de las instalaciones que ocasionen el incumplimiento de los requisitos de habitabilidad de apartado 1, letra c), del artículo 3.

c. Seguro de daños materiales o seguro de caución, para garantizar, durante diez años, el resarcimiento de los daños materiales causados en el edificio por vicios o defectos que tengan su origen o afecten a la cimentación, los soportes, las vigas, los forjados, los muros de carga y otros elementos estructurales, y que comprometan directamente la resistencia mecánica y estabilidad del edificio».

9 CARRASCO PERERA, A. Derecho de la Construcción y la Vivienda, $6^{\text {a }}$ edición, Editorial Dilex S.L, Madrid, 2008, p. 413.

10 PACHECO JIMÉNEZ, M.N recalca que el seguro decenal es una garantía compleja que requiere un importante grado de especialización e infraestructura en las entidades aseguradoras, dado que abarca un dilatado período de tiempo y conlleva el manejo de elevadas sumas aseguradas, existiendo una importante concentración en esta modalidad aseguraticia, pues las cinco primeras compañías en el ranking de pólizas contratadas representan más del ochenta y cinco por ciento de la cuota de mercado. Los seguros en el proceso de la edificación, $1^{\text {a }}$ edición, Editorial La Ley, Madrid, 2008.

11 Dichos elementos se enumeran sin ánimo exhaustivo en el artículo 17.1.a) de la LOE, que hace referencia a la cimentación, los soportes, las vigas, los forjados o los muros de carga 
años $)^{12}{ }^{13}$. Quedan, por tanto, excluidos de la cobertura del seguro obligatorio los vicios de habitabilidad, debiendo ser considerados como tales aquellos defectos que, excediendo de las imperfecciones corrientes, impiden o dificultan la utilización del edificio para la finalidad que le es propia ${ }^{14}$; así como los defectos de terminación o acabado, que son aquellos de escasa entidad constructiva, económica y funcional, rayanos en lo tolerable ${ }^{15}$.

El seguro decenal, según la aludida disposición adicional, es obligatorio únicamente para los «edificios cuyo destino principal sea el de vivienda», si bien no especifica en qué consiste el mismo. No obstante, para discernir qué usos pueden entenderse incluidos en el mencionado destino y cuáles no, podemos acudir a la Resolución-Circular de 3 de diciembre de 2003, de la Dirección General de los Registros y del Notariado (en adelante DGRN), que da una serie de pautas al respecto a los notarios y a los registradores, a fin de indicarles los casos en que deben exigir la acreditación de la constitución de la garantía a la hora de autorizar e inscribir determinadas escrituras públicas (las de declaración de obra nueva, según exige el artículo 20.1 de la ley, y la de transmisión inter vivos, según dispone la propia disposición adicional segunda).

Con tal finalidad, se establecen como criterios básicos los siguientes: «(...) a) En los edificios de viviendas en alquiler, es exigible el seguro decenal en todo caso, al tratarse de edificios destinados a vivienda. b) En las residencias de estudiantes, de la tercera edad y otras de carácter residencial, supuesto que plantea mayor dificultad; se entiende que aun cuando tienen una vocación de permanencia de las personas en dichas residencias, a diferencia de otras que pueden tener un carácter más transitorio (como por ejemplo, residencias sanitarias o alojamientos hoteleros), lo cierto es que no tienen el carácter de vivienda, a pesar de estar destinadas a un uso residencial (cfr. Art. 2 de la Ley), por lo que no puede exigirse dicho seguro; siguiendo así el criterio mantenido por este Centro Directivo en Resolución de 8 de febrero de 2003 en relación con una residencia geriátrica, donde ya se puso de manifiesto la dificultad de distinguir los conceptos

12 Algunos autores ponen de manifiesto que, en la configuración del vicio estructural, no tiene sentido exigir que la estabilidad del edificio quede afectada de modo actual, pues ello equivaldría a requerir, para que se pueda aplicar el régimen de responsabilidad que la LOE establece, que se hubiese producido el abandono del inmueble por sus moradores o que hubiese recaído la declaración administrativa de ruina, consecuencias que resultarían excesivas y poco ajustadas a las finalidades de la misma. Véase, DEL ARCO TORRES y PONS GONZÁLEZ, Derecho de la Construcción, Editorial Comares, S.L, $4^{\mathrm{a}}$ edición, Granada, 2000, p. 434.

13 Los tribunales se han pronunciado expresamente acerca de que, por tener la consideración de vicios estructurales, es preceptiva la contratación del seguro decenal en los supuestos de ausencia de protección contra incendios, tanto de las zonas comunes del edificio como de las viviendas (STS, Sala de lo Civil, de 5 de mayo de 2014, Tirant Online -en adelante, TOL- 4.418.306); de vicios que afectan a la estructura de la cimentación del edificio, al haberse situado directamente sobre la tierra de relleno, sin anclaje sobre tierra firme, con lo que la construcción no resulta sólida en ninguno de sus puntos, provocando continuos movimientos y resquebrajaduras (SAP de Madrid, Sección 11a , de 20 de octubre de 2015 (TOL 5.561.349); de defectos en la cimentación que afectan a elementos fundamentales o estructurales y que comprometen la estabilidad del edificio (SAP de Toledo, Sección 2a ${ }^{\text {a }}$, de 22 de junio de 2016 (TOL 5.818.129); o de defecto en el diseño de la estructura proyectada, con insuficiencia de la armadura y disminución de los coeficientes de seguridad (SAP Cádiz, Sección 8a, de 29 de marzo de 2017, TOL 6.119.276).

14 La Audiencia Provincial de Madrid ha confirmado de modo explícito la ausencia de responsabilidad de la compañía aseguradora en un supuesto de defectos localizados en los muros de cerramiento, el suelo del paseo peatonal y la piscina de la edificación, dado que solo afectan a la habitabilidad, por lo que no deben ser objeto de aseguramiento en la póliza (Sentencia de 3 de mayo de 2016, Sección 13a, -TOL 457.098-), así como en el de humedades detectadas en un garaje y que no comprometían la resistencia mecánica del edificio (Sentencia de 26 de septiembre de 2016, Sección $10^{\mathrm{a}}$ ).

15 ORTÍ VALLEJO, A: «La responsabilidad civil por defectos constructivos en la Ley de Ordenación de la Edificación». En Cuestiones actuales sobre responsabilidad civil, Aranzadi Thomson Reuters, Navarra, 2013, p. 125. 
de vivienda y residencia que plantea en este punto la ley ${ }^{16}$. c) En los edificios en régimen de aprovechamiento por turnos de bienes inmuebles; es exigible el seguro, porque aunque en ellos no puede constituirse un domicilio habitual, sí tienen la consideración de vivienda, ya sea ésta la segunda o la tercera, y vaya a ser ocupada por una o varias familias. Además, si bien no puede emplearse el término propiedad, el aprovechamiento por turnos de bienes inmuebles se configura como un auténtico derecho real que debe hacerse constar en escritura pública e inscribirse en el Registro de la Propiedad (cfr. Ley 42/1998, de 15 de diciembre, sobre Derechos de aprovechamiento por turno de bienes inmuebles de uso turístico y normas tributarias ${ }^{17}$ ). d) En cuanto a los edificios mixtos (oficinas-viviendas); si el destino principal del edificio es el de vivienda no cabe duda de la obligatoriedad del seguro, incluso en aquellos supuestos en que el número de oficinas (a las que pueden equipararse las plazas de garaje, trasteros y locales comerciales) sea superior al de viviendas».

En cuanto al último supuesto, el de edificios mixtos, la Resolución no aclara qué debe entenderse por «destino principal de vivienda». Entiendo que concurre tal destino cuando las unidades privativas destinadas a vivienda, independientemente de su número, ocupan en el edificio una mayor extensión superficial que las dedicadas a otros usos. Con todo, no faltan autores, como RUIZ-RICO RUIZ, que, traspasando la literalidad de la ley, defienden que la disposición adicional segunda no puede ser interpretada en el sentido de que la existencia de un destino principal diferente del de vivienda autorice a entender que el seguro no es obligatorio, argumentando que todos los inmuebles en que haya un destino de vivienda, sea principal o no, resultan alcanzados por el mismo, pues sostener lo contrario supondría desvirtuar el espíritu protector de la ley ${ }^{18}$.

El apartado 2 de la disposición adicional segunda atribuye al Gobierno la facultad de establecer por medio de real decreto la obligatoriedad de los seguros trienal y anual

16 La RDGRN de 8 de febrero de 2003 distingue los conceptos de vivienda y de residencia geriátrica (centrados ambos en la satisfacción de las condiciones de la vida doméstica de las personas) desde dos puntos de vista: su distinta naturaleza y el fin de protección de la norma. En cuanto al primer enfoque, la Resolución afirma que «el sentido del término vivienda se tiñe de un significado familiar o de tipo familiar, en cuanto sede física en que se asienta un grupo heterogéneo de personas más o menos numeroso ligadas entre sí principal, aunque no necesaria ni exclusivamente, por vínculos de parentesco, y con un amplio grado de autonomía en la organización no sólo de su sistema de vida sino también de configuración de este espacio vital en que consiste la vivienda, en su decoración, amueblamiento, etc. Sería la idea de vivienda a la que más se aproximan las normas protectoras de la intimidad, comenzando por el artículo 18.2 de la Constitución. Y en este sentido no puede asimilarse al concepto de vivienda una residencia de la tercera edad». Desde la segunda óptica, la Resolución sostiene que : «No parece que puedan entenderse como destinatarios de sus garantías (se refiere a la de Disposición Adicional Segunda, que fija los términos de obligatoriedad del seguro decenal ) otros que no sean los consumidores de lo que normalmente se entiende como vivienda en el mercado, el bien constituido por una edificación habitable destinada a servir de soporte residencial, en la que ese consumidor invierte gran parte de sus ahorros y para cuya adquisición suele endeudarse por largos años, interés ciertamente digno de protección y muy distinto al de una empresa mercantil que construye o adquiere un edificio para desarrollar en él una actividad empresarial como lo es la explotación de una residencia geriátrica, las más de las veces con una fuerte inversión que normalmente irá precedida del adecuado asesoramiento jurídico y técnico del que no gozan los consumidores ordinarios en el mercado de la vivienda».

17 En la actualidad, tal derecho se regula en la Ley 4/2012, de 6 de julio, de contratos de aprovechamiento por turno de bienes de uso turístico, de adquisición de productos vacacionales de larga duración, de reventa y de intercambio y normas tributarias.

18 RUIZ-RICO RUIZ, J.M. La responsabilidad civil en la Ley de Ordenación de la Edificación, Editorial Comares, S.L, Granada, 2002, pp. 39 a 41. Afirma el autor que «(...) Si la ley ha querido que todo propietario de un inmueble -en especial el adquirente de viviendas- pueda disfrutar de una serie de garantías contra los defectos constructivos, sobre todo contra la ruina de su inmueble, carece de toda lógica que la construcción de un conjunto inmobiliario con múltiples destinos pueda dar pie a la desprotección de quienes adquirieron una parte del mismo». 
para los edificios que tengan como destino principal el de vivienda, así como el carácter preceptivo de cualquiera de los tres seguros para edificios destinados a cualquier uso distinto del de vivienda. A día de hoy, el Gobierno no ha hecho uso de tal autorización. A mi juicio es urgente que el poder ejecutivo confiera carácter preceptivo al seguro trienal en edificios con destino a vivienda, si se quiere dotar a la garantía establecida por la LOE de eficacia verdaderamente tuitiva de los adquirentes de inmuebles (mayoritariamente consumidores), pues el acervo de las sentencias dictadas por nuestros juzgados y tribunales revela que los vicios de habitabilidad son los que con mayor frecuencia se producen en las construcciones.

\section{B) Exclusiones por razones objetivas y subjetivas}

Aparte de la actual exclusión del seguro por razón del destino del edificio, existen otras que toman en consideración diversas circunstancias, pudiendo ser éstas clasificadas en objetivas, o que atienden al tipo de obra a ejecutar, y subjetivas, o que se refieren al agente de la edificación que interviene.

Veamos, en primer lugar, la exclusión de tipo objetivo. En su redacción originaria la LOE no estableció salvedad alguna, de ahí que la constitución del seguro decenal fuese inicialmente exigible a todas las obras incluidas en su ámbito de aplicación, recogido en el artículo 1.2, y, en consecuencia, tanto a las obras de nueva construcción como a las de ampliación, modificación, reforma o rehabilitación que alteren la configuración arquitectónica del edificio (entendiendo que tal alteración se produce en las obras de intervención total, así como en las de intervención parcial que produzcan una variación esencial de la composición general exterior del edificio, la volumetría o el conjunto del sistema estructural, o tengan por objeto cambiar el uso del mismo).

Posteriormente, el artículo 105 de la Ley 53/2002, de 30 de diciembre, de Medidas Fiscales, Administrativas y del Orden Social, introdujo un tercer párrafo en el apartado uno de la disposición adicional segunda de la LOE, que es del tenor literal siguiente: "Tampoco será exigible la citada garantía en los supuestos de rehabilitación de edificios destinados principalmente a viviendas para cuyos proyectos de nueva construcción se solicitaron las correspondientes licencias de edificación con anterioridad a la entrada en vigor de la presente Ley». La norma parece superflua, pues ya la disposición transitoria primera establecía que lo dispuesto en la ley (y, por tanto, lo relativo al seguro obligatorio) sería de aplicación a las obras de nueva construcción y a las obras en los edificios existentes para cuyos proyectos se solicitase la correspondiente licencia de edificación a partir de su entrada en vigor. Pese a su aparente inutilidad, dicha norma soluciona uno de los problemas que siempre planteó la exigencia del seguro decenal en las obras de rehabilitación o reforma. Este tipo de obras supone una actuación constructiva sobre un edificio ya existente, que puede ser incluso muy antiguo y cuyo sistema estructural pudo no haber sido sometido a la supervisión de los organismos de control de calidad, seguimiento que exigen las aseguradoras para así poder conocer realmente y valorar el riesgo que asumen, por lo que en la práctica sería muy difícil, por no decir imposible, encontrar una compañía que se prestase a asegurar las obras de rehabilitación. No obstante, al exigir el nuevo precepto sensu contrario la conclusión del seguro, no para las obras de rehabilitación cuya licencia se solicite tras la entrada en vigor de la LOE, sino para las obras de rehabilitación en edificios para cuyos proyectos de nueva construcción se solicitó la correspondiente 
licencia después de la entrada en vigor de la misma, el mencionado problema queda obviado, pues la compañía aseguradora que contrató el seguro decenal por nueva construcción sí habría podido seguir el proceso edificativo inicial y, en consecuencia, podría asegurar sin problema las obras de rehabilitación, dado que conoce el sistema estructural del edificio y los riesgos que asume.

Si bien la nueva norma resuelve el problema apuntado, deja subsistentes otros, como son los que a continuación se indican.

$1^{\mathrm{o}}$. Se produce una alteración en la estructura subjetiva del contrato de seguro, pues si bien la ley exige con carácter general que el tomador del seguro sea el promotor (artículo 19.2 y 3), tal imposición no parece posible en las obras de rehabilitación, que serán acometidas pasado un tiempo desde la terminación del edificio y cuando aquél probablemente ya haya enajenado los diversos elementos privativos, con lo que se plantea el problema de determinar quién tiene la obligación de contratarlo. Entiendo que, dado que las obras de reforma o rehabilitación serán afrontadas por el propietario del inmueble (la comunidad de propietarios si estuviese acogido al sistema de propiedad horizontal), debe entrar en juego el régimen de exención del autopromotor, que más adelante se expone.

$2^{\circ}$. Es posible que se produzca una superposición de seguros, situación que se dará en aquellos casos en que las obras de rehabilitación se realicen como consecuencia de haberse producido un siniestro en el marco del seguro contratado a raíz del levantamiento del edificio. Cuando la obra de rehabilitación, que exige la contratación de su propio seguro, se lleva a cabo en concepto de indemnización del seguro anterior por daños provocados por vicios de la construcción, es posible que el plazo de vigencia de éste aún no se haya agotado. Ante dificultades como esta, CARRASCO PERERA defiende que la reforma de la disposición adicional segunda de la LOE ha supuesto la supresión de la obligatoriedad del seguro para todas las obras de rehabilitación19; postura que parece difícilmente sustentable a la vista de la unívoca redacción del precepto. Entiendo que el problema, al menos desde el punto de vista teórico, es más aparente que real, pues se trata de seguros con un objeto de cobertura diferente, con lo que su coexistencia en el tiempo no debiera plantear mayores problemas. El seguro contratado en segundo lugar cubrirá el riesgo de los daños provocados en el edificio por vicios de las obras de rehabilitación, mientras que el concluido en primer lugar seguirá cubriendo el riesgo de los daños procedentes de vicios de las obras de nueva construcción. Más dificultades se plantearán desde el punto de vista práctico, pues, detectado un nuevo vicio de la construcción, surgirá la cuestión de determinar si es imputable a las obras de edificación o a las de reforma, la cual no será de fácil resolución en muchas ocasiones. En aquellos casos en que la causa del vicio no pueda circunscri-

19 CARRASCO PERERA, A, op. cit, 2008, p. 412. Sostiene que: «Tales consideraciones habrán pesado en el legislador, que en el artículo 105 de la Ley 53/2002 (aunque mediante un infame texto legal, que parece decir todo lo contrario de lo que pretende) ha suprimido la obligatoriedad del seguro para las obras de rehabilitación, incluso si las licencias de edificación se hubieran solicitado con anterioridad a esta Ley 35/2002». 
birse claramente a las obras de nueva construcción o a las de rehabilitación, dos soluciones podrían apuntarse: o bien aplicar la doctrina de la concurrencia de causas, o bien entender que la causa es la obra de reforma, como última y eficiente.

Desde el punto de vista subjetivo, la LOE dispensa la constitución del seguro decenal obligatorio cuando el promotor es una Administración Pública; pues el artículo 1.3 declara que cuando las Administraciones Públicas actúen como agentes de la edificación se regirán por la legislación de contratos del sector público, siendo la LOE de aplicación supletoria en todo lo no previsto, salvo en materia de garantías de suscripción obligatoria.

Algunos autores entienden que dicha previsión se establece por la consideración de que las Administraciones Públicas son solventes y que, por tanto, los particulares tienen asegurada la reparación de los daños materiales ocasionados en sus viviendas por los defectos de construcción ${ }^{20}$. Tal opinión resulta difícilmente asumible, no sólo porque la realidad de los tiempos en que vivimos se ha encargado de demostrar lo contrario, sino porque la solvencia de ciertas Administraciones (como la local) siempre ha estado en entredicho; además de que la prontitud para cobrar la correspondiente indemnización por parte de los perjudicados no parece posible, a la vista del procedimiento administrativo interno que la Administración debe seguir para poder comprometer pagos. Desde mi punto de vista, circunstancias como las expuestas no han podido pasar desapercibidas para el legislador, de modo que la exoneración de la constitución de las garantías no se basa en la presunción de liquidez sino que obedece al régimen de privilegio que tradicionalmente se ha concedido a la Administración en diversos ámbitos.

La redacción originaria de la LOE exigía la contratación del seguro decenal a todos los promotores, tanto al que construía edificios para introducirlos en el tráfico jurídico, como al que impulsaba la construcción de un inmueble para destinarlo a satisfacer sus propias necesidades permanentes de vivienda. Sin embargo, pronto se cayó en la cuenta de que no tenía sentido exigirlo a este último, pues no se intuye, al menos mientras conserve la titularidad de la vivienda, ningún conflicto de intereses que justifique la intervención protectora de la ley. Carece de toda lógica exigir al autopromotor la constitución de un seguro que le proteja frente a sí mismo, o, lo que es igual, requerirle el establecimiento de una garantía que él podría estar obligado a satisfacer en último término (pues la aseguradora, en su caso, puede repetir frente a él la indemnización abonada). Además, tal exigencia conlleva para el autopromotor un considerable incremento del coste de construcción de su vivienda, incremento que no encuentra contrapartida en una utilidad clara para él. Por tales razones, la Ley 53/2002, de 30 de diciembre, introdujo un segundo párrafo en el primer punto de la disposición adicional segunda de la LOE, que es del tenor siguiente: «No obstante, esta garantía no será exigible en el supuesto del autopromotor individual de una única vivienda unifamiliar para uso propio. Sin embargo, en el caso de producirse la transmisión inter vivos dentro del plazo previsto en la letra a, del artículo 17.1 (diez años contados desde la recepción de la obra sin reservas o desde la subsanación de éstas), el autopromotor, salvo pacto en contrario, quedará obligado a la contratación de la garantía a que se refiere el párrafo anterior (el seguro decenal) por el tiempo que reste para completar los diez años. A estos efectos, no se autorizarán ni inscribirán en

20 STRUCH STRUCH, J. Las responsabilidades en la construcción: regímenes jurídicos y jurisprudencia, $4^{\mathrm{a}}$ edición, Editorial Aranzadi, S.A, Navarra, 2011, p. 869. 
el Registro de la Propiedad escrituras públicas de transmisión inter vivos sin que se acredite y testimonie la constitución de la referida garantía, salvo que el autopromotor, que deberá acreditar haber utilizado la vivienda, fuese expresamente exonerado por el adquirente de la constitución de la misma».

Como vemos, la ley, para eximir al autopromotor de la contratación del seguro, exige la concurrencia de los siguientes requisitos:

a. Que se trate de un autopromotor individual, condición que la ley no equipara a la persona física. La propia DGRN, en Resoluciones de 9 de julio y 3 de diciembre de 2003, 28 de octubre de 2004 y 6 de abril de 2005, ha afirmado que del concepto de autopromotor individual no debe excluirse a las personas jurídicas, debiendo entenderse tal individualidad en sentido estrictamente numérico ${ }^{21}$.

b. Que la promoción lo sea de una única vivienda unifamiliar. Tal requisito no debe ser entendido en el sentido de que la vivienda tenga que ser destinada a servir de morada al promotor y a su círculo familiar más próximo, pudiendo éste acogerse a la dispensa de la contratación del seguro cuando vaya a destinarla a usos diferentes, tales como los de despacho profesional o domicilio social. Y ello porque si la disposición adicional segunda no exige, al menos de momento (mientras el Gobierno no haga uso de la facultad de extensión que se le concede), la constitución del seguro decenal para edificios cuyo destino principal no sea el de vivienda, carece de sentido exigírsela al autopromotor en la misma circunstancia. Además, la interpretación estricta imposibilitaría incluir en la dispensa al autopromotor que sea persona jurídica, pues, independientemente de que ésta ha de contar con un domicilio social, no tiene necesidad de vivienda que haya de satisfacer ${ }^{22}$.

En cuanto al requisito de la unicidad, entiendo que no debe ser interpretado en el sentido de que procede la exención del seguro sólo cuando se trate de la primera vivienda que promueve el dispensado, de modo que aquélla no fuese aplicable a la promoción

21 En la Resolución de 3 de diciembre de 2003, la DGRN afirma que: «El concepto de promotor individual no debe llevar a interpretaciones excesivamente rigoristas, de manera que cuando la ley se refiere a él, según sostuvo este Centro Directivo en Resolución de 9 de julio de 2003, deben entenderse comprendidos en dicho concepto tanto las personas fisicas como las personas jurídicas, dado que en última instancia éstas son una sola entidad, son «individuales» siguiendo un criterio numérico». Tal Resolución admite incluso la exención de la obligación de asegurar en el caso de autopromotores que se asocian para la construcción de sus propias viviendas independientes, sin los presupuestos fácticos que dan lugar a la división horizontal o en solares diferentes.

Por su parte, la RDGRN de 27 de febrero de 2014, en aras de la interpretación flexible del requisito de la individualidad que propugna, afirma que con una interpretación literal y estricta de autopromotor individual «se incurriría en contradicción valorativa respecto del caso de persona jurídica promotora, que puede ser pluripersonal. Y no puede llevarse al extremo de exigir el seguro decenal por el hecho de que la construcción no se haya promovido por una sola persona, pues llevaría al absurdo de exigirlo en caso de que los promotores sean personas casadas en régimen de separación de bienes o convivientes en la misma vivienda».

Y la RDGRN de 16 de mayo de 2014 admite la exoneración de la obligación de contratar el seguro decenal en el supuesto de una única vivienda unifamiliar construida en régimen de copropiedad o comunidad ordinaria por tres hermanos.

22 La vinculación que la ley hace al uso de vivienda o residencial a efectos de exoneración de la contratación del seguro, ligazón que no considero determinante a tal fin como he indicado, ha llevado a algún autor a exigir el requisito de que la vivienda sea de titularidad privada, rechazando la exención en las que sean de titularidad pública. DE LA FUENTE, M.S, «Responsabilidades y garantías del autopromotor individual y colectivo según la vigente Ley de Ordenación de la Edificación (1)», El Consultor Inmobiliario, No 71, 2006, p.12. 
de un bloque de viviendas, ni al promotor profesional que ha impulsado la construcción de otras viviendas con anterioridad. Se trata de un requisito que, al igual que los demás, debe ser interpretado a la luz del fin de protección de la norma, que no es otro que el interés de los terceros adquirentes de viviendas en contar con un medio adicional de amparo frente a los vicios o defectos de construcción en las mismas. Por tanto, el promotor profesional debe poder eximirse del otorgamiento de la garantía cuando, por las circunstancias del caso concreto, pueda racionalmente inferirse que la vivienda no va a ser introducida en el tráfico comercial. Así, por ejemplo, cuando el promotor se reserva una sola vivienda en una urbanización de chalets adosados, sin que cuente en la zona con otra de similares características, o cuando, aun teniendo ya vivienda en propiedad, efectúe tal reserva en promociones ubicadas en zonas aptas para emplazar una segunda vivienda o de temporada (la costa, la montaña, etc...). En este sentido se pronuncia también la DGRN ${ }^{23}$.

c. Y, finalmente, que la vivienda con respecto a la que se solicita la exención vaya a estar destinada a uso propio del autopromotor. Algún autor propone una interpretación extensiva de esta premisa, entendiendo que la norma debe vincularse con el ámbito familiar o afectivo más cercano del autopromotor, incluyendo dentro del uso de la vivienda que permite obtener la exención aquel que hagan, separadamente de él, sus hijos, padres u otros familiares ${ }^{24}$.

El autopromotor que, aun reuniendo los requisitos expuestos, decida transmitir la vivienda, viene obligado a contratar el seguro si aún no ha transcurrido el plazo de diez años desde que se entienda producida la recepción de la obra y precisamente por el tiempo que falte para completarlo; pues, de lo contrario, el notario no podría autorizar la correspondiente escritura ni el registrador inscribirla en el Registro de la Propiedad, salvo que el adquirente, de modo expreso, exonere al autopromotor de la constitución de la garantía. En la práctica, tal exoneración se producirá con frecuencia si el adquirente tiene interés en disfrutar de los beneficios proporcionados por la fe pública registral, pues resultará sumamente difícil encontrar una compañía que esté dispuesta a asegurar una vivienda terminada, cuyo proceso de edificación no ha podido conocer ni controlar en modo alguno. Aunque el adquirente exima al autopromotor de contratar el seguro, la ley exige que éste acredite haber utilizado la vivienda, sin establecer plazo mínimo para dicho uso, lo que podrá llevarse a cabo por cualquiera de los medios probatorios admitidos en derecho, recogidos en el artículo 299 de la Ley de Enjuiciamiento Civil (documentos públicos o privados, testigos, medios de reproducción de la palabra, el sonido y la imagen, etc) ${ }^{25}$.

23 Así, en la Resolución de 3 de diciembre de 2003 afirma que: «Por lo que respecta al concepto de «vivienda destinada a uso propio», se entiende por tal toda aquella que tienda a este uso por parte del autopromotor, siendo indiferente que se trate de primera o segunda vivienda, y aunque se trate de una residencia meramente temporal...»

24 STRUCH STRUCH, J. op. cit, p. 876

25 En cuanto a dichos medios de prueba, no parece suficiente la simple manifestación del interesado relativa a que habita o ha habitado la vivienda, dada su nula objetividad. No obstante, tal evidencia es de fácil obtención a través de documentos de uso corriente, tales como el certificado de empadronamiento, los recibos relativos a los consumos referidos a servicios con que cuente el inmueble (agua, electricidad, gas, o teléfono), que figuren a nombre del autopromotor o de miembros de su círculo familiar más próximo, los cuales, al no exigir la ley un instrumento probatorio completo, deben considerarse apropiados a los efectos aludidos. 


\section{EXCLUSIÓN DE COBERTURA}

Delimitado en el epígrafe anterior el ámbito del seguro obligatorio, es preciso ahondar en su configuración legal con el estudio de las exclusiones de su cobertura. La propia ley establece en el apartado 9 del artículo 19 los daños que no quedan cubiertos por el seguro que establece, los cuales pueden clasificarse del siguiente modo.

$1^{\circ}$. Los daños distintos de los materiales ocasionados en el edificio; es decir, los daños diferentes a los resarcibles a través de la acción que la LOE instaura, exclusión que resulta lógica pues no cabe imponer a la compañía aseguradora la indemnización de unos daños de los que los agentes de la edificación no responden conforme a la ley. En este grupo se incluyen los daños corporales (letra a), los daños ocasionados a inmuebles contiguos o adyacentes al edificio (letra b) y los daños causados a bienes muebles situados en el edificio (letra c).

$2^{\circ}$. Los daños ocasionados por modificaciones u obras realizadas en el edificio una vez finalizado el proceso edificativo; es decir, después de producido el acto de recepción de la obra, que, obviamente, no serán imputables al promotor ni a ningún otro agente de la edificación, con la única salvedad de los daños que se produzcan en las operaciones de subsanación de los defectos observados en aquél (letra d).

$3^{\circ}$. Los daños que no sean imputables causalmente a la intervención de los agentes de la edificación en la obra, entre los que la ley menciona expresamente los desperfectos ocasionados por mal uso o falta de mantenimiento adecuado del edificio (letra e), los daños que tengan su origen en un incendio o explosión, salvo que su génesis obedezca a defectos de las instalaciones propias del edificio (letra g), así como los daños ocasionados por caso fortuito, fuerza mayor, acto de tercero o por el propio perjudicado por el daño (letra $h$ ).

$4^{\circ}$. Los gastos que nada tienen que ver con el proceso de la construcción, ni, por consiguiente, con defectos cometidos durante el mismo por los agentes que en él intervienen, como los necesarios para el mantenimiento del edificio del que ya se ha hecho la recepción (letra f).

$5^{\circ}$. Y, por último, los siniestros que tengan su origen en partes de la obra sobre las que haya reservas recogidas en el acta de recepción, mientras tales reservas no hayan sido objeto de subsanación y las subsanaciones queden reflejadas en un acta nueva suscrita por los firmantes del acta de recepción (letra i).

\section{MODOS DE CUMPLIMIENTO}

La ley deja en libertad al obligado para elegir la modalidad de seguro que desee contratar: daños, caución o garantía financiera; si bien establece para los dos primeros una serie de condiciones que, en algunos aspectos, se apartan del régimen general establecido en la Ley del Contrato de Seguro de 8 de octubre de 1980 (en adelante LCS). 


\section{A) Condiciones que para el seguro de daños exige el artículo 19.2 de la LOE}

a. En el supuesto de daños ocasionados por vicios estructurales y por defectos de habitabilidad (seguro no obligatorio a día de hoy), el tomador del seguro ha de ser el promotor, mientras que en el caso de daños producidos por defectos de ejecución que afecten a elementos de acabado (que tampoco es obligatorio), la condición de tomador recae sobre el constructor.

La cualidad de asegurado corresponde a quien sea en cada momento propietario del inmueble o de las unidades en que éste se divide, por lo que tendrá tal condición el promotor hasta que transmita el inmueble y los sucesivos adquirentes a partir de la primera y ulteriores ventas. Se trata de que la posición del asegurado sea asumida a lo largo de la vigencia del seguro por quien pueda realmente resultar perjudicado por los vicios de la construcción, motivo por el que no será de aplicación la previsión contenida en el artículo 35.1 de la LCS, que permite al asegurador rescindir el contrato dentro de los quince días siguientes a aquel en que tenga conocimiento de la transmisión del objeto asegurado.

En puridad de ideas, como pone de manifiesto CARRASCO PERERA, el asegurado es individualmente cada uno de los adquirentes de las unidades privativas del edificio y no la comunidad de propietarios en conjunto ${ }^{26}$. La cuestión no es baladí, pues, para facilitar las reclamaciones individuales, las pólizas deberían distribuir el importe de la suma asegurada (y en su caso, de la franquicia) entre las distintas unidades registrales, cosa que no sucede en la práctica, en que dicha suma se fija en consideración al edificio entero.

b. La prima ha de estar desembolsada en el momento de la recepción de la obra, instante en el que despliega eficacia la cobertura del seguro. No obstante, cuando el asegurador y el tomador pacten el fraccionamiento del pago de la prima en cualquier período posterior a tal fecha, el impago por parte de éste de la segunda y/o las siguientes fracciones es inoponible por la compañía aseguradora al asegurado en caso de que el siniestro llegue a producirse, la cual no puede resolver el contrato ni darlo por extinguido, como tampoco por suspendida la cobertura, debiendo cumplir su obligación indemnizatoria. De este modo, la LOE, en su tarea de configurar un específico régimen para el seguro de daños por defectos de la construcción, exceptúa en este ámbito la aplicación del artículo 15.2 de la $\mathrm{LCS}^{27}$.

No especifica la ley qué ocurre en los supuestos de que, a fecha de recepción de la obra, el tomador no haya abonado la prima única o el primer pago de la prima fraccionada. ¿Significa esto que, en tales casos, la falta de pago es oponible por la entidad ase-

26 CARRASCO PERERA, A. op. cit, 2008, p. 415.

27 Según el artículo 15 de la LCS: «Si por culpa del tomador la primera prima no ha sido pagada, o la prima única no lo ha sido a su vencimiento, el asegurador tiene derecho a resolver el contrato o a exigir el pago de la prima debida en vía ejecutiva con base en la póliza. Salvo pacto en contrario, si la prima no ha sido pagada antes de que se produzca el siniestro, el asegurador quedará liberado de su obligación.

En caso de falta de pago de una de las primas siguientes, la cobertura del asegurador queda suspendida un mes después del día de su vencimiento. Si el asegurador no reclama el pago dentro de los seis meses siguientes al vencimiento de la prima se entenderá que el contrato queda extinguido. En cualquier caso, el asegurador, cuando el contrato esté en suspenso, sólo podrá exigir el pago de la prima del periodo en curso.

Si el contrato no hubiere sido resuelto o extinguido conforme a los párrafos anteriores, la cobertura vuelve a tener efecto a las veinticuatro horas del día en que el tomador pagó su prima». 
guradora al asegurado que reclama la indemnización? La doctrina se encuentra dividida entre quienes sostienen que el sentido de la norma debe llevar a entender que también en estos casos la falta de pago es inoponible por el asegurador ${ }^{28}$, postura a la que me adhiero, y entre quienes defienden que el impago de la prima o de su primera fracción conlleva la aplicación del artículo 15 de la LCS, y, en consecuencia, el asegurador puede resolver el contrato o reclamar el pago de la prima, quedando liberado de su obligación si ésta no hubiese sido pagada antes de la producción del siniestro ${ }^{29}$.

c. No resulta de aplicación a los daños materiales ocasionados por defectos de construcción la normativa reguladora de los riesgos extraordinarios, contenida en el artículo 4 de la Ley 21/1990, de 19 de diciembre, precepto que ha sido derogado por el Real Decreto Legislativo 7/2004, de 29 de octubre, por el que se aprueba el Texto Refundido del Estatuto Legal del Consorcio de Compensación de Seguros, cuyo artículo 6.3.c), en relación con los riesgos extraordinarios sobre las personas y los bienes, no considera indemnizables por el Consorcio los daños debidos a vicio o defecto propio de la cosa asegurada.

\section{B) Condiciones que para el seguro de caución exige el artículo 19.3 de la LOE}

a. La cualidad de tomador corresponde a los mismos agentes de la edificación que en el seguro de daños: el promotor y, en su caso, el constructor. En cambio, los asegurados son siempre los sucesivos adquirentes del edificio o de parte del mismo; por lo que, a diferencia del de daños, en el seguro de caución no se permite que dicha posición pueda ser ocupada por el promotor ${ }^{30}$.

Semejante disposición de la ley no ocasiona ningún problema cuando el tomador es el propio promotor (seguro decenal por defectos estructurales y trienal por defectos de habitabilidad), pero sí produce distorsiones cuando el tomador es el constructor (seguro anual por defectos de ejecución que afecten a elementos de acabado), pues mientras el promotor no venda la vivienda, cosa que puede tardar bastante tiempo en suceder, no habrá ninguna persona que ocupe la posición de asegurado, y, en consecuencia, nadie podrá reclamar al asegurador el pago de la correspondiente indemnización en caso de producirse el siniestro. En efecto, no resulta en absoluto descabellado pensar que, en tiempos como los que corren, el promotor puede tardar en vender la vivienda más de tres años (un año en el que, como máximo, el daño se debe producir, y dos años de prescripción de la acción dimanante del contrato de seguro, según el artículo 23 de la LCS $^{31}$ ) a contar

28 CARRASCO PERERA, A. Comentarios a la Ley de Ordenación de la Edificación, 2a edición, Editorial Aranzadi, S.A, Navarra, 2001. pp. 416 y 417. Afirma que si el legislador no se ha pronunciado sobre los supuestos de impago de la prima única o del primer plazo de la prima fraccionada es porque no resulta imaginable que el asegurador pueda llegar a emitir la póliza en tales circunstancias.

En el mismo sentido, Op. cit, 2008, p. 414

29 STRUCH STRUCH, J. op. cit, pp. 912 y 913.

30 Es en la determinación del asegurado en la que la SAP de Zaragoza, Sección 2a , de 15 de abril de 2014 (TOL 4.425.197) hace hincapié para distinguir el seguro de daños del de caución en un supuesto en el que la naturaleza del contrato concluido era discutida, afirmando que «se trata de un seguro de daños materiales (artículo 19.2 $L O E)$, como se desprende claramente de que los asegurados son el promotor y los sucesivos adquirentes (...), en el caso del seguro de caución (artículo 19.3 LOE) los asegurados son siempre los sucesivos adquirentes del edificio o parte del mismo».

31 El artículo 23 de la LCS fija el plazo de prescripción de las acciones derivadas del contrato de seguro en dos años si se trata del seguro de daños y de cinco años si el seguro es de personas. 
desde la recepción de la obra, momento en el que la compañía aseguradora ya no podría ser compelida al cumplimiento de su obligación indemnizatoria.

b. La prima debe estar pagada en el momento de la recepción de la obra, al igual que en el seguro de daños, por lo que se puede dar aquí por reproducido todo lo expuesto sobre el particular a propósito de éste.

c. La compañía aseguradora ha de indemnizar al asegurado a primer requerimiento.

d. Y el asegurador no podrá oponer al asegurado las excepciones que puedan corresponderle contra el tomador del seguro.

Los dos últimos requisitos deben ser tratados conjuntamente, dado que están íntimamente relacionados. En cuanto a qué valor deba darse a la orden de pago de la indemnización a primer requerimiento, CARRASCO PERERA entiende que dos interpretaciones son posibles: $1^{\text {a }}$ ) equiparar el requerimiento del asegurado a la producción del siniestro, sin exigirle prueba al respecto; y $2^{\mathrm{a}}$ ) entender que el requerimiento, no sólo sustituye a la prueba del siniestro, sino que, además, obliga al asegurador a hacer frente a la indemnización sin posibilidad de articular excepciones para neutralizar el derecho del asegurado, de modo que aquél primero debería pagar, agilizando enormemente el cobro del resarcimiento por parte de éste, y en un momento posterior podría discutir cualquier cuestión relativa a dicho pago ${ }^{32}$.

El autor se inclina por la segunda interpretación, es decir, por la inoponibilidad de excepciones al asegurado por parte del asegurador cuando aquél le requiere de pago. No obstante, para no llegar a resultados inadmisibles, propone determinar aquellas excepciones cuya utilización por parte del asegurador, pese al mandato legal, no puede ser cuestionada, entre las que incluye todo lo relativo al montante del capital asegurado; si bien deja fuera de dicho ámbito inobjetable las excepciones que conforme a la LCS corresponden al asegurador contra el asegurado no tomador, tales como el incumplimiento de la obligación legal de comunicación de agravación de riesgo ${ }^{33}$ y el incumplimiento del deber de salvamento ${ }^{34}$, salvo que tales omisiones obedezcan a la intención dolosa del asegurado de perjudicar al asegurador.

32 CARRASCO PERERA, Op. cit, 2001, pp. 424 y 425.

33 Una vez que el tomador del seguro ha declarado al asegurador, antes de la conclusión del contrato y de acuerdo con el cuestionario que éste le someta, las circunstancias por él conocidas que puedan influir en la valoración del riesgo, el artículo 11 de la LCS le impone (o al asegurado cuando sea persona distinta del tomador) la obligación de comunicar al asegurador las circunstancias que lo agraven, en cuyo caso el asegurador puede proponer una modificación del contrato o rescindirlo con observancia de las condiciones y plazos que establece el artículo 12 de dicho cuerpo legal.

34 El artículo 17 de la LCS impone al tomador, o al asegurado si fuese persona distinta, la obligación de adoptar medidas dirigidas a minimizar las consecuencias del siniestro. Establece que «El asegurado o el tomador del seguro deberán emplear los medios a su alcance para aminorar las consecuencias del siniestro. El incumplimiento de este deber dará derecho al asegurador a reducir su prestación en la proporción oportuna, teniendo en cuenta la importancia de los daños derivados del mismo y el grado de culpa del asegurado.

Si este incumplimiento se produjera con la manifiesta intención de perjudicar o engañar al asegurador, éste quedará liberado de toda prestación derivada del siniestro.

Los gastos que se originen por el cumplimiento de la citada obligación, siempre que no sean inoportunos o desproporcionados a los bienes salvados serán de cuenta del asegurador hasta el límite fijado en el contrato, incluso si tales gastos no han tenido resultados efectivos o positivos. En defecto de pacto se indemnizarán los gastos efectivamente originados. Tal indemnización no podrá exceder de la suma asegurada. 
Sin embargo, la dicción de la ley es clara y si la letra c) del artículo 19.3 sólo impide al asegurador oponer las excepciones que puedan corresponderle contra el tomador del seguro, en mi opinión ha de entenderse que el compromiso de indemnizar a primer requerimiento no impide a la compañía aseguradora oponer al asegurado las excepciones que tenga contra él. La interpretación conjunta de los requisitos recogidos en el artículo 19.3.b) y c) milita a favor de tal consideración.

Vistas las condiciones que la ley fija para cada uno de los seguros entre los que el tomador puede optar, el párrafo 4 del artículo 19 sienta otro requisito que es de aplicación a todos ellos, consistente en que, una vez que la cobertura del seguro tome efecto, el contrato no puede rescindirse ni resolverse de muto acuerdo antes de que transcurran los plazos en que obligatoriamente debe estar en vigor (diez, tres y un año dependiendo del tipo de defecto de construcción). De este modo se fortalece la posición del asegurado y se le protege frente a los pactos que en su contra puedan concluir las partes contratantes del seguro, tomador y asegurador.

A robustecer la situación del asegurado contribuye también la norma contenida en el apartado 8 del artículo 19, que impide la introducción en el contrato de seguro anual o por defectos de ejecución atinentes a los elementos de acabado, de franquicias o u otros pactos que limiten de algún modo la responsabilidad del asegurador. Ello obedece seguramente a la consideración de que si se admitiesen franquicias en este tipo de seguro, cuyos daños suelen ser de escasa cuantía, la reparación de los mismos recaería, íntegramente o en su mayor parte, en el asegurado. En los contratos de seguro decenal y trienal, si se incluyen franquicias, su cuantía no puede ser superior al 1\% del capital asegurado de cada unidad registral.

\section{SUMAS ASEGURADAS Y VÍA DE REGRESO}

La LOE también hace indicación expresa de la cuantía de las sumas aseguradas para cada clase de seguro. El apartado 5 del artículo 19 las fija en un 5\% del coste final de la ejecución material de la obra para el seguro anual, un 30\% del mismo para el seguro trienal y un $100 \%$ para el seguro decenal. En los tres casos se establece que en el valor del coste final de la ejecución de la obra han de incluirse los honorarios profesionales (se entiende, de los agentes de la edificación intervinientes). En el supuesto del seguro, sea de daños, de caución o de garantía financiera, para garantizar el resarcimiento por los menoscabos ocasionados por defectos en los elementos estructurales, en que la ley exige que la suma asegurada cubra el 100\% del coste final de ejecución, resulta obvio que el legislador quiso preservar la total indemnidad del asegurado frente a los vicios más graves de la construcción, de modo que éste dispusiese de los medios necesarios para acometer la reconstrucción del edificio, si ésta fuese necesaria por derrumbe del mismo. Para cumplir tal objetivo, STRUCH STRUCH entiende que la suma asegurada ha de extenderse también al importe de las tasas e impuestos que necesariamente deben pagarse para la construcción de un edificio, así como cualesquiera otros gastos de carácter inevitable.

El asegurador que en virtud del contrato sólo deba indemnizar una parte del daño causado por el siniestro, deberá reembolsar la parte proporcional de los gastos de salvamento, a menos que el asegurado o el tomador del seguro hayan actuado siguiendo las instrucciones del asegurador». 
Estima este autor que la suma asegurada debe cubrir incluso el importe del seguro decenal obligatorio que la LOE obligaría a concertar al promotor al abordar la reedificación del edificio derruido ${ }^{35}$.

La suma asegurada representa, según el artículo 27 de la LCS, el límite máximo a pagar por el asegurador en cada siniestro. Es fácil que, a consecuencia de la revaloración del edificio, fenómeno que hace unos años se producía ficticiamente de un día para otro por efecto de la burbuja inmobiliaria que se gestó en nuestro país entre los años $1997 \mathrm{y}$ 2007, se produzcan situaciones de infraseguro; es decir, que, en el momento de ocurrencia del siniestro, la suma asegurada no alcance el valor de la construcción objeto de cobertura. Cuando se origina tal coyuntura, la LCS establece que el asegurador sólo viene obligado a indemnizar el daño causado en la misma proporción en la que la suma asegurada cubre el interés asegurado (artículo 30.1), con lo que podría verse frustrado el designio del legislador de 1999 de que, en caso de siniestro, el asegurado pueda hacer frente a la subsanación del vicio constructivo con el importe de la indemnización.

Pese a que la LCS ofrece medios para prevenir el infraseguro, como la estimación del interés asegurado en las pólizas (artículo 28) o la inclusión en ellas del pacto expreso de que la suma asegurada cubra siempre de modo pleno el valor del interés (artículo 29), la LOE no contiene ninguna previsión al respecto. Durante la tramitación de la ley se presentó una enmienda, la número 128, del Grupo Parlamentario Socialista, en la se proponía excluir la aplicación de la regla proporcional del artículo 30.1 de la LCS para el supuesto de que se incurra en infraseguro ${ }^{36}$. La misma no prosperó. Pero ello no quiere decir que, aun cuando no se hayan pactado cláusulas de estimación o de adaptación del valor del interés al de la suma asegurada, el asegurado vaya a sufrir detrimento alguno en su patrimonio, pues aquella cantidad que no cubra la indemnización del seguro podrá reclamársela por las vías ordinarias a los agentes de la edificación que participaron en el proceso edificativo.

No obstante, dado que se presenta como elevada la posibilidad de que el asegurador y el tomador no incluyan en la póliza los aludidos remedios, bien por desidia, bien por interés, habida cuenta de que su incorporación posiblemente conllevaría un encarecimiento de la prima, el recurso a los tribunales para obtener de los agentes de la edificación la parte de indemnización no recibida de la compañía aseguradora me parece un remedio claramente insuficiente, pues el asegurado tardará un tiempo excesivo en lograr una sentencia firme. Por ello, la supresión de la regla proporcional que proponía la aludida enmienda me parece plenamente acertada, pues la misma serviría de estímulo a las partes contratantes del seguro para la previsión en la póliza de soluciones a la probable

35 STRUCH STRUCH, J, Op. cit, pp. 916 y 917.

El autor fundamenta su opinión en que «si se produce la destrucción total del edificio y todavía quedan en el mismo unidades privativas sin haberse transmitido a terceros y el edificio se tiene que volver a construir, entendemos que se tendrá que volver a concertar este seguro pues si no se hace así no se podrán inscribir las ventas de las unidades privativas que se mantengan en el edificio propiedad del promotor y, por lo tanto, será otro coste necesario para la construcción (en este caso, reconstrucción) del edificio».

36 El texto de la enmienda número 128 es el siguiente: «No obstante, podrá pactarse la actualización del indicado límite de garantía, por el tomador del seguro o cualquier persona que ostente el título de propietario del edificio. De no actualizarse el valor asegurado, de conformidad con el apartado anterior, en ningún caso será aplicable la reducción de las indemnizaciones prevista en el artículo 30 de la Ley del Contrato de Seguro por falta de actualización del capital asegurado». Boletín Oficial de las Cortes Generales, Congreso de los Diputados, de 21 de mayo de 1999. 
e indeseable situación de infraseguro. En consecuencia, de lege ferenda parece oportuna una reforma en el sentido indicado.

La solución por la que se ha decantado la jurisprudencia de las audiencias provinciales (no me consta que el Tribunal Supremo se haya pronunciado al respecto) es la de considerar que la regla del artículo 30.1 de la LCS no resulta aplicable al seguro decenal, argumentando que otra cosa «implicaría limitar la responsabilidad inherente a las obligaciones asumidas por el promotor en materia de vicios o defectos de estructura, de obligatorio aseguramiento en la $\mathrm{LOE}_{»^{37}}$. Estimo que tal conclusión no es técnicamente correcta por dos razones. Primera, porque confunde la responsabilidad del tomador con las cuestiones relativas a la suma asegurada, que son aspectos totalmente diferentes. Y segunda, porque el artículo 19 de la LOE tiene por objeto la configuración de un régimen específico para el seguro que nos ocupa, de modo que no habiendo dejado en tal cometido sin efecto la regla proporcional del régimen general (como, en cambio, sí deja otras), el operador jurídico tampoco puede hacerlo, máxime si se tiene en cuenta que durante la tramitación parlamentaria de la ley fue rechazada una enmienda que pretendía precisamente su supresión.

Y por último hay que aludir a una cuestión: producido el siniestro y abonada la correspondiente indemnización por la compañía aseguradora, ésta se subroga en la posición del asegurado contra el agente de la edificación responsable del vicio generador del daño e incluso contra la compañía que haya asegurado su responsabilidad civil. Así se desprende del artículo 43 de la LCS, no exceptuado de aplicación en este ámbito, y del artículo 18 de la LOE, que regula la acción de repetición. Este último establece que la acción que corresponde a los aseguradores contra los agentes de la edificación prescribe en el plazo de dos años desde la firmeza de la resolución judicial que condene al responsable a indemnizar los daños, o a partir de la fecha en la que se hubiera procedido a la indemnización de forma extrajudicial. Tal facultad subrogatoria priva de sentido a la posibilidad de que los agentes de la edificación que han sido judicialmente interpelados pidan la llamada al pleito de la compañía aseguradora que no fue demandada. Aunque dicha llamada en garantía no parece posible por los términos en que se expresa la disposición adicional séptima de la LOE, que la limita a los agentes que hayan tenido intervención material en el proceso edificativo, carece además de efecto práctico, pues la aseguradora que resulte condenada y abone la indemnización siempre podrá repetir contra los agentes responsables.

\section{MEDIDAS COACTIVAS DESTINADAS A CONSEGUIR LA CONTRATACIÓN DEL SEGURO OBLIGATORIO}

La LOE establece, con diverso grado de eficacia, una serie de medidas para forzar al obligado a contratar el seguro (el promotor y, en su caso, el constructor) a cumplir con tal exigencia. Son las que a continuación se indican.

$1^{\text {a }}$. El incumplimiento conlleva, según el artículo 19.7, la obligación de responder personalmente al obligado a suscribir las garantías

37 Véanse la SAP de Granada de 12 de enero de 2018 (TOL 6.600.888) y la SAP de Ciudad Real de 5 de diciembre de 2018 (TOL 7.030.279) 
Este precepto ha provocado perplejidad en toda la doctrina, puesto que no añade nada nuevo al régimen general de responsabilidad por vicios de la construcción. En efecto, los obligados a suscribir las garantías por defectos de la edificación responden de las consecuencias de éstos, como cualquier otro deudor, con todos sus bienes presentes o futuros. Se trata de una manifestación del principio de responsabilidad patrimonial universal (artículo 1911 del CC) y no haría falta que un precepto de la ley especial así lo estableciese. Teniendo en cuenta los antecedentes de la LOE, concretamente el Anteproyecto de 1994, pudiera pensarse que la intención del legislador fue la de hacer responder del incumplimiento de la obligación de contratar el correspondiente seguro, de modo personal, a los administradores de las sociedades promotoras y/o constructoras. Sin embargo, esta tesis no puede sostenerse a la vista del tenor literal del precepto, como tampoco por el hecho de haberse rechazado durante la tramitación parlamentaria de la ley una enmienda, la número 129, que pretendía que del incumplimiento respondiesen solidariamente la sociedad obligada a concertar el seguro y los administradores que lo hubiesen sido en los cuatro años inmediatamente anteriores.

CARRASCO PERERA, en un loable esfuerzo por intentar dar alguna utilidad al precepto, propone la interpretación del artículo 19.7 en términos del artículo 17; en el sentido de que el promotor o constructor que omitan la contratación del preceptivo seguro vendrán obligados a responder personalmente con el agente o agentes a los que fuese imputable el vicio aunque no se den las condiciones de la responsabilidad solidaria ${ }^{38}$, que, conforme al citado precepto, son dos: que no pueda individualizarse la causa de los daños materiales o que se pruebe la concurrencia de culpas sin que pueda precisarse el grado de intervención de cada agente en el daño producido ${ }^{39}$.

La interpretación de este autor puede servir para salvar la eficacia de la norma en el supuesto de que el infractor sea el constructor, pero no cuando lo sea el promotor, pues éste, por imperativo legal, responde siempre frente a los adquirentes de modo solidario con los demás agentes de los daños causados por los defectos de la construcción.

$2^{\mathrm{a}}$. Los notarios no deben autorizar, ni los registradores de la propiedad inscribir, las escrituras de declaración de obra nueva, sin que previamente se acredite la constitución de la garantía, según establece el artículo 20.140

38 CARRASCO PERERA, A. Op. cit, 2001. pp. 386 y 387.

39 Conviene apuntar que el empleo del término «culpa» por el artículo 17.3 de la LOE no resulta congruente con el sistema de responsabilidad que instaura, que es claramente objetiva, por lo que no debiera hablar de concurrencia de culpas en la producción del daño sino de «causas».

40 El artículo 20.1 de la LOE es del tenor literal siguiente: «No se autorizarán ni se inscribirán en el Registro de la Propiedad escrituras públicas de declaración de obra nueva de edificaciones a las que sea de aplicación esta Ley, sin que se acredite y testimonie la constitución de las garantías a que se refiere el artículo 19».

Resulta evidente la deficiente redacción del precepto, pues la medida que establece no es aplicable a todas las edificaciones incluidas en el ámbito de aplicación de la LOE, sino sólo a aquellas para las que la disposición adicional segunda establece la obligatoriedad de contratar el seguro decenal, es decir, las que tengan como principal destino el de vivienda. 
Se trata de una medida realmente eficaz, pues si el promotor, por no acreditar la contratación del seguro, no puede otorgar la escritura de declaración de obra nueva, no podrá tampoco llevar a cabo actos como el establecimiento del título constitutivo de la propiedad horizontal o la distribución de la eventual carga hipotecaria entre las unidades privativas resultantes, quedando así privado de la posibilidad de realizar su finalidad económica esencial, que no es otra que la venta de los pisos y locales susceptibles de aprovechamiento independiente.

La DGRN, en Resoluciones como la de 3 de diciembre de 2003, ha precisado que la escritura que no puede ser autorizada ni inscrita si previamente no se acredita la constitución de la garantía es la de declaración de obra nueva terminada, no afectando por tanto a la escritura de declaración de obra nueva en construcción ${ }^{41}{ }^{42}$. Por otro lado, en la Resolución de 11 de septiembre de 2000, estableció que la mencionada prueba debe realizarse de tres formas: mediante la presentación de la propia póliza del contrato, complementada con el documento en que se acredite su entrada en vigor, mediante un certificado expedido por la entidad aseguradora acreditativo de la constitución y vigencia del contrato, o mediante el suplemento de entrada en vigor del seguro, en el que se particularicen las condiciones del contrato.

$3^{\mathrm{a}}$. Por último, la imposibilidad, durante el plazo de prescripción de las acciones del artículo 18, de cerrar la hoja abierta al promotor persona física o de inscribir la extinción de la sociedad promotora en el Registro Mercantil sin acreditar, con respecto a todos los edificios cuya construcción hubiesen impulsado, la constitución de la preceptivas garantías (artículo 20.2 ${ }^{43}$ ).

Coincido con STRUCH STRUCH en que el plazo de prescripción a que se refiere el precepto, durante cuya vigencia no se pueden practicar las

41 «En cuanto al momento en que sea exigible la constitución del seguro, y de acuerdo con la doctrina reiterada de este Centro Directivo (entre otras, Resolución de 20 de marzo de 2000), los Notarios y Registradores de la Propiedad tan sólo exigirán la constitución de las garantías a que se refiere el artículo 19 de la Ley de Ordenación de la Edificación al autorizar o inscribir, respectivamente, las escrituras de declaración de obra nueva terminada o las actas de finalización de obras.

No se exigirá por tanto la prestación de la garantía en las escrituras de declaración de obra nueva en construcción, lo cual es coherente por otro lado con la inexistencia de bien asegurable de daños mientras no existe edificación. Si bien sí deberá hacerse constar al pie del título el carácter obligatorio de la constatación registral de la finalización de la obra, momento en el que procederá la exigencia de tales garantías; siendo obligación del Registrador de la Propiedad por tanto, al inscribir la obra nueva en construcción, la de advertir sobre la futura exigencia de la prestación del seguro en la inscripción de la declaración de terminación de la obra, sin que se pueda prejuzgar al inscribir la obra nueva en construcción si va a haber o no dispensa de la prestación de tales garantías, ya que los requisitos de la Disposición Adicional Segunda tienen que concurrir en el momento de la terminación de la obra y no antes, por mucho que en algunas escrituras a efectos de la exención fundada en la autopromoción, ya se anticipe que se cumplen todos los requisitos previstos en la Ley...»

42 Sin embargo, DÍAZ FRAILE se muestra contrario a la posibilidad de inscripción de la declaración de obra nueva en construcción, dado que la LOE difiere el control de los seguros a la constancia registral de la terminación de la obra. «El tratamiento registral de la obra nueva en la Ley 8/2007, de 28 de mayo, del Suelo», Boletín del Colegio de Registradores de España, No 41, 2007.

43 Según el artículo 20.2 de la LOE, "Cuando no hayan transcurrido los plazos de prescripción de las acciones a que se refiere el artículo 18, no se cerrará en el Registro Mercantil la hoja abierta al promotor individual ni se inscribirá la liquidación de las sociedades promotoras sin que se acredite previamente al Registrador la constitución de las garantías establecidas por esta Ley, en relación con todas y cada una de las edificaciones que hubieran promovido». 
mencionadas inscripciones en el Registro de la Propiedad, debe ser el tiempo máximo posible en el que por hipótesis cabe el ejercicio de las acciones que contempla la ley ${ }^{44}$; es decir, la totalidad de los distintos plazos de garantía más el plazo de prescripción de la acción propiamente dicho. Sólo con esta interpretación se puede llevar tal mandato a la práctica, pues juega con fechas ciertas y datos objetivos, aunque no resuelva a priori de modo adecuado el supuesto de que se hayan producido actos interruptivos de la prescripción.

No parece, sin embargo, que esta última medida tenga gran eficacia desde el momento en que el Registrador carece de medios para conocer todos y cada uno de los edificios cuya promoción ha sido llevada a cabo por el empresario individual o la entidad societaria, con respecto a los cuales debería exigir la acreditación de la constitución de la garantía por todo el plazo indicado.

\section{CONCLUSIONES}

Primera: El seguro que la LOE exige constituir es, a elección del tomador, un seguro de daños, de caución o de garantía financiera; seguros que deben permanecer vigentes durante los plazos de garantía establecidos por la misma, de diez, tres y un año, desde la recepción de la obra, para responder respectivamente de los daños ocasionados por vicios estructurales, defectos de habitabilidad y vicios de ejecución que afecten a elementos de terminación o acabado.

Segunda: En los vicios que afecten a elementos de acabado, la LOE permite al promotor sustituir la contratación del seguro por una retención del 5\% del coste de la ejecución material de la obra; medida de nula eficacia protectora para los adquirentes del inmueble en el plazo de un año desde la recepción, pues si el promotor se negase a invertir el importe de aquella en su corrección no tendrían más remedio que acudir a los tribunales.

Tercera: En la actualidad únicamente el seguro decenal es preceptivo y sólo para edificios cuyo destino principal sea el de vivienda, en tanto el Gobierno no haga uso de la facultad de extender su obligatoriedad al trienal y/o al anual, así como a edificaciones dedicadas a usos diferentes. Conforme a la doctrina registral, el destino principal de vivienda concurre en los edificios de viviendas en alquiler y en los que están sometidos al régimen de aprovechamiento por turnos, pero no en los destinados a residencia de estudiantes, geriátrica o de otro tipo, en los que predomina el aspecto empresarial o lucrativo. En los edificios mixtos concurre el indicado destino cuando las unidades privativas destinadas a vivienda ocupen una considerable mayor extensión que las destinadas a otros usos.

Cuarta: El urgente que el Gobierno haga uso de la habilitación que le concede el apartado 2 de la disposición adicional segunda de la LOE y confiera carácter preceptivo al seguro trienal en edificios destinados a vivienda, si se quiere dotar a la garantía introducida por la LOE de eficacia verdaderamente tuitiva de los adquirentes de los mismos.

Quinta: El hecho de que la actual redacción de la LOE excluya de la exigencia del seguro decenal las obras de reforma de los edificios para cuyos proyectos de nueva

44 STRUCH STRUCH, J. Op. cit, p. 929. 
construcción se solicitaron las correspondientes licencias de edificación con anterioridad a su entrada en vigor solventa el problema que planteaba su redacción originaria, que no recogía tal excepción, y que atiende a la dificultad de encontrar una compañía dispuesta a asegurar la obra llevada a cabo en un edificio cuyas condiciones le son desconocidas.

Sexta: Quedan exentos de la obligación de contratar el seguro decenal el promotor que tenga la condición de administración pública y el autopromotor; éste último siempre que se trate de un ente (persona física o jurídica) individual, que la promoción sea de una única vivienda unifamiliar (si bien no tiene que ser destinada a servir de morada, pudiendo ser dedicada a otros usos) y que esté dirigida a uso propio del autopromotor, pero debiendo contratar la garantía cuando transmita la vivienda dentro del plazo de diez años a contar desde la recepción de la obra y por el tiempo que falte para completarlo.

Séptima: En el seguro de caución, la limitación de la posición del asegurado a los sucesivos adquirentes del inmueble, con exclusión del promotor (marginación que no se produce en el seguro contra daños), produce distorsiones cuando el tomador es el constructor (en el seguro anual), pues mientras el promotor no venda la vivienda no existirá asegurado propiamente dicho ni, por tanto, persona que pueda reclamar la indemnización, si el siniestro llegara a producirse.

Octava: La regla proporcional, prevista en el artículo 30.1 de la LCS para el caso de infraseguro, debe ser suprimida de lege ferenda en el seguro que nos ocupa, pues, aunque el asegurado puede reclamar a los agentes de la edificación intervinientes en el proceso constructivo la parte de indemnización no recibida de la compañía aseguradora, tal solución se revela claramente insuficiente dada la tardanza habitual en obtener una sentencia firme.

Novena: La ley establece diversas medidas destinadas a conseguir que el sujeto obligado suscriba el seguro, de las que únicamente resulta eficaz la consistente en la imposibilidad de autorizar e inscribir en el Registro de la Propiedad la escritura pública de declaración de obra nueva si previamente no se acredita tal contratación, dado que, al no ser viable en tales circunstancias la inscripción constitutiva del derecho real de hipoteca, el promotor no podría obtener la financiación necesaria para desarrollar el proceso edificativo.

\section{BIBLIOGRAFÍA}

Cabanillas Sánchez, A. «La responsabilidad civil por vicios de la construcción en la Ley de Ordenación de la Edificación». Anuario de Derecho Civil, Madrid, 2000, páginas 405 a 5510.

Carrasco Perera, A. Derecho de la Construcción y la Vivienda, 6 a edición, Editorial Dilex, S.L, Madrid, 2008.

Comentarios a la Ley de Ordenación de la Edificación, 2a edición, Editorial Aranzadi, S.A, Navarra, 2001.

De La Fuente, M. S. «Responsabilidades y garantías del autopromotor individual y colectivo según la vigente Ley de Ordenación de la Edificación (1)», El Consultor Inmobiliario, Nº 71, 2006, páginas 3 a 25.

Del Arco Torres Y Pons González. Derecho de la Construcción, Editorial Comares, S.L, 4a edición, Granada, 2000.

DíAz Fraile, J. M. «El tratamiento registral de la obra nueva en la Ley 8/2007, de 28 de mayo, del Suelo», Boletín Oficial del Colegio de Registradores de España, No 41, 2007, páginas 3787 a 3812. 
Ortí VAllejo, A. «La responsabilidad civil por defectos constructivos en la Ley de Ordenación de la Edificación». En Cuestiones actuales sobre responsabilidad civil, Aranzadi Thomson Reuters, Navarra, 2013, páginas 115 a 157.

Pacheco Jiménez, M. N. Los seguros en el proceso de la edificación, $1^{\text {a }}$ edición, Editorial La Ley, Madrid, 2008.

Ruiz-Rico Ruiz, J. M. La responsabilidad civil en la Ley de Ordenación de la Edificación, Editorial Comares, S.L, Granada, 2002.

STRUCh Struch, J. Las responsabilidades en la construcción: regímenes jurídicos y jurisprudencia, $4^{\mathrm{a}}$ edición, Editorial Aranzadi, S.L, Navarra, 2011.

YzQuierdo Toslada, M. «¿Qué cubren en realidad los seguros de caución para la construcción en las cooperativas de viviendas?. Un comentario disidente a la Sentencia del Tribunal Supremo (Pleno Sala Primera) de 13 de septiembre de 2013», Revista de la Asociación Española de Abogados Especializados en Responsabilidad Civil y Seguro, No 49, 2014, páginas 25 a 36. 